\title{
TRANSIENT HEAT CONDUCTION PROBLEMS USING B.I.E.M.
}

\author{
VICENTE ROURES \\ Civil Engineering Division, INITEC, Madrid, Spain \\ and \\ ENRIQUE ALARCON \\ Polytechnical University, Madrid, Spain
}

\begin{abstract}
A method, using boundary elements, is presented as a solution to plane transient heat conduction. The proposed method considers the governing equation to be a Helmholtz's equation and solves the problem of time variation using step by step integration. A numerical procedure is developed and its effectiveness verified. Several examples are provided and their results compared with the theoretical ones.
\end{abstract}

\section{INTRODUCTION}

The application of Boundary Integral Equation Method (B.I.E.M.) to problems of transient heat conduction started in 1969 with a paper by Rizzo and Shippy[1] in which the properties of Laplace transform were applied; later, in 1970, Shaw [2] and, in 1972, Chang et al.[3] solved the problem by using a time-dependent solution. In 1977 Combescure and Lachat[4] repeated the use of integral transforms and in 1979 Wrobel and Brebbia [5] used a time-dependent fundamental solution and a weighted residual formulation.

This paper presents the formulation for two-dimensional isotropic continuous solid using the Helmholtz's equation as well as the Green's theorem, with step by step computation in the time domain.

In the context of boundary technique, the idea was proposed by Brebbia and Walker[8] but they did not present any result.

As there appears a domain term in the formulation it is necessary to evaluate some integrals inside the volume by establishing an internal cell subdivision. However only known quantitites are involved in these integrals with the unknown values limited at the boundary, and the cell system does not increment the size of the system of equations to be solved.

A procedure to eliminate the domain integration in connection with the method described in (5) has been recently published [9].

\section{FORMULATION}

The equation that governs the transient heat conduction phenomena in a domain $D$ with boundary $\partial D$ is

$$
k \nabla^{2} \phi=\rho c \frac{\partial \phi}{\partial t}
$$

or

$$
K \nabla^{2} \phi=\frac{\partial \phi}{\partial t}
$$

where $\phi$ is the temperature; $t$ is the time; $k$ is the thermal conductivity; $\rho$ is the density; $c$ is the specific heat; and $K$ is the thermometric conductivity $K=k / \rho c$. The boundary conditions are known in every moment

$$
\begin{gathered}
\phi=\bar{\phi} \quad \text { on } \partial D_{1} \\
q=\frac{\partial \phi}{\partial n}=\bar{q} \quad \text { on } \partial D_{2}
\end{gathered}
$$

and so are the initial conditions inside the domain

$$
\phi=\phi_{0} \text { in } D
$$

$q$ is the heat flux; $n$ is the normal to the boundary; and $\partial D=\partial D_{1}+\partial D_{2}$.

The basic equation is obtained from (1) through a finite difference approach in the time domain so that the equation

$$
K \nabla^{2} \phi=\frac{\phi \Delta_{t}-\phi_{0}}{\Delta t}
$$

can be solved at every time step.

The boundary formulation can be obtained looking for a $\psi$ such that

$$
K \nabla^{2} \psi-\frac{\psi}{\Delta t}+\Delta=0
$$

where $\Delta$ is the Dirac function presenting a singularity at the point where (4) is being applied.

The eqn (5) can be compared with the Helmholtz's equation in the form of a modified Bessel equation. The solution of (5), called fundamental solution, is-in two dimensions-the following.

$$
\begin{gathered}
\psi=\frac{1}{2 \pi K} K_{0}\left[\frac{r}{\sqrt{ }(K \Delta t)}\right] \\
\frac{\partial \psi}{\partial r}=\frac{-1}{2 \pi K} \frac{1}{\sqrt{ }(K \Delta t)} K_{1}\left[\frac{r}{\sqrt{ } K \Delta t)}\right] \\
\frac{\partial \psi}{\partial n}=\frac{-1}{2 \pi K} \frac{d}{r} \frac{1}{\sqrt{ } k(\Delta t)} K_{1}\left[\frac{r}{\sqrt{ }(k \Delta t)}\right]
\end{gathered}
$$


where $K_{0}$ is the modified Bessel function of second kind and zero order; $K_{1}$ is the modified Bessel function of second kind and first order; $r$ is the distance between two points; and $d$ is the distance between the point under study and the observed boundary element.

Applying the 2nd Green's theorem it is possible to write.

$$
\begin{array}{r}
\phi(J)-\int_{D} \frac{1}{\Delta t} \psi(H, J) \phi_{0}(H) \mathrm{d} V(H) \\
+\int_{\partial D} K \phi(G) \frac{\partial \psi}{\partial n}(G, J) \mathrm{d} S(G) \\
=\int_{\partial D} K \psi(G, J) \frac{\partial \phi}{\partial n}(G) \mathrm{d} S(G) \\
J, H \in D G \in \partial D .
\end{array}
$$

When the point $J$ is on $\partial D$ there appears a singularity $(r \rightarrow 0)$ which can be elucidated by the usual procedure of isolation of the point under study by a circle-two dimensions-of radius $\zeta \rightarrow 0$.

If the point $J$ is on the boundary and $\partial D$ is the boundary of the circle, (9) can be written as

$$
\begin{aligned}
& \phi(J)-\int_{D} \frac{1}{\Delta t} \psi(H, J) \phi_{0}(H) \mathrm{d} V(H) \\
&+\int_{\partial D-\partial D \epsilon} K \phi(G) \frac{\partial \psi}{\partial n}(G, J) \mathrm{d} S(G) \\
&+\int_{\partial D_{\epsilon}} K \phi(G) \frac{\partial \psi}{\partial n}(G, J) \mathrm{d} S(G) \\
&=\int_{\partial D-\partial D_{\epsilon}} K \psi(G, J) \frac{\partial \phi}{\partial n}(G) \mathrm{d} S(G) \\
&+\int_{\partial D_{\epsilon}} K \psi(G, J) \frac{\partial \phi}{\partial n}(G) \mathrm{d} S(G) \\
& H \in D \quad J, G \in \partial D
\end{aligned}
$$

but for smooth boundaries

$$
\begin{gathered}
\lim _{\epsilon \rightarrow 0} \int_{\partial D_{\epsilon}} \phi(G) \frac{\partial \psi}{\partial n}(G, J) \mathrm{d} S(G)=\frac{-1}{2} \phi(J) \\
\lim _{\epsilon \rightarrow 0} \int_{\partial D_{\epsilon}} \psi(G, J) \frac{\partial \phi}{\partial n}(G) \mathrm{d} S(G)=0 .
\end{gathered}
$$

If a sharp corner exists in the boundary the first integral will have a value $T^{*}(J)$ and putting

$$
T(J)=1-T^{*}(J)
$$

it is possible to write the fundamental equation to be discretized as below.

$$
\begin{array}{r}
T(J) \phi(J)-\int_{D} \frac{1}{\Delta t} \psi(H . J) \phi(H) \mathrm{d} V(H) \\
+\int_{\partial D} K(\phi) G \frac{\partial \psi}{\partial n}(G, J) \mathrm{d} S(G) \\
\int_{\partial D} K \psi(G, J) \frac{\partial \phi}{\partial n}(G) \mathrm{d} S(G) \\
H \in D \quad J, G \in \partial D
\end{array}
$$

(13) and (9) are the basic pair of equations that allows the solution of the problem on the boundary and inside the domain respectively.

\section{DISCRETIZATION}

The isoparametric formulation described elsewhere [6] is used when discretizing the boundary as well as the field variables.

That is, the geometry is interpolated by

$$
\begin{aligned}
& X(\xi)=N g(\xi) X_{g} \\
& Y(\xi)=N g(\xi) Y_{g}
\end{aligned}
$$

while the potential and flux are assumed to vary according to

$$
\begin{aligned}
\phi(\xi) & =N g(\xi) \phi_{g} \\
q(\xi) & =N g(\xi) q_{g}
\end{aligned}
$$

inside each element; where, as usual,

$$
\begin{gathered}
N_{1}(\xi)=\frac{-1}{2}(\xi-1) \\
N_{2}(\xi)=\frac{1}{2}(\xi+1)
\end{gathered}
$$

and

$$
\mathrm{d} S_{g}=\frac{1 g}{2} \mathrm{~d} \xi
$$

where $1 g$ is the length of the $g$ element.

Inside the domain the integral is evaluated assuming quadrilateral cells.

$$
\begin{gathered}
X(\xi, \eta)=M_{h}(\xi, \eta) X_{h} \\
Y(\xi, \eta)=M_{h}(\xi, \eta) Y_{h}
\end{gathered}
$$

where the interpolation functions are the bilinear ones.

$$
\begin{aligned}
& M_{1}(\xi, \eta)=\frac{1}{4}(1-\xi)(1-\eta) \\
& M_{2}(\xi, \eta)=\frac{1}{4}(1+\xi)(1-\eta) \\
& M_{3}(\xi, \eta)=\frac{1}{4}(1+\xi)(1+\eta) \\
& M_{4}(\xi, \eta)=\frac{1}{4}(1-\xi)(1+\eta)
\end{aligned}
$$

and

$$
\mathrm{d} V_{h}=\frac{1}{8}\left|\begin{array}{ccc}
X_{1} & Y_{1} & 1 \\
X_{3} & Y_{3} & 1 \\
X_{4}-X_{2} & Y_{4}-Y_{2} & 0
\end{array}\right| \mathrm{d} \xi \mathrm{d} \eta
$$

On the contrary the function $\phi_{0}$ is assumed to have a constant value inside each cell $\phi_{0 h}$, so that the system of equations can be put in the form.

$$
\begin{aligned}
T(J) \phi(J) & -\sum_{h=1}^{m} C+\sum_{g=1}^{n}\left(A_{1} A_{2}\right)\left(\begin{array}{c}
\phi_{g}(G) \\
\phi_{g}(G+1)
\end{array}\right) \\
= & \left.\sum_{g=1}^{m}\left(B_{1} B_{2}\right)\right)\left(\begin{array}{c}
q_{g}(G) \\
q_{g}(G+1)
\end{array}\right)
\end{aligned}
$$


where

$$
\begin{aligned}
& A_{1}=K \int_{\partial D_{g}} N_{1}(\xi) \frac{\partial \psi_{g}}{\partial n}(J) \frac{1_{g}}{2} \mathrm{~d} \xi \\
& A_{2}=K \int_{\partial D_{g}} N_{2}(\xi) \frac{\partial \psi_{g}}{\partial n}(J) \frac{1_{g}}{2} \mathrm{~d} \xi \\
& B_{1}=K \int_{\partial D_{g}} N_{1}(\xi) \psi_{g}(J) \frac{1_{g}}{2} \mathrm{~d} \xi \\
& B_{2}=K \int_{\partial D_{g}} N_{2}(\xi) \psi_{g}(J) \frac{1 g}{2} \mathrm{~d} \xi \\
& C=\frac{1}{\Delta t} \phi_{o h} \int_{D_{h}} \psi_{h}(J) \frac{1}{8}\left|\begin{array}{ccc}
X_{1 h} & Y_{1 h} & 1 \\
X_{3 h} & Y_{3 h} & 1 \\
X_{4 h}-X_{2 h} & Y_{4 h}-Y_{2 h} & 0
\end{array}\right| \mathrm{d} \xi \mathrm{d} \eta
\end{aligned}
$$

The computation of $A_{1} A_{2} B_{1} B_{2} C$ can be done either in closed form or by numerical procedures. This paper uses the second type except when an element is viewed from itself. The expressions are the following.

\section{Numerically}

$$
\begin{aligned}
& A_{1}=\frac{d}{8 \pi} \frac{1_{g}}{\sqrt{ }(K \Delta t)}\left[\sum_{i=1}^{j}\left(\xi_{i}-1\right) \frac{1}{r_{i}} K_{1}\left(\frac{r_{i}}{\sqrt{ }(K \Delta t)}\right) \omega_{i}\right] \\
& A_{2}=\frac{-d}{8 \pi} \frac{1_{g}}{\sqrt{ }(K \Delta t)}\left[\sum_{i=1}^{j}\left(\xi_{i}+1\right) \frac{1}{r_{i}} K_{1}\left(\frac{r_{i}}{\sqrt{ }(K \Delta t)}\right) \omega_{i}\right] \\
& B_{1}=\frac{-1_{g}}{8 \pi}\left[\sum_{i=1}^{j}\left(\xi_{i}-1\right) K_{0}\left(\frac{r_{i}}{\sqrt{ }(K \Delta t)}\right) \omega_{i}\right] \\
& B_{2}=\frac{1_{g}}{8 \pi}\left[\sum_{i=1}^{j}\left(\xi_{i}+1\right) K_{0}\left(\frac{r_{i}}{\sqrt{ }(K \Delta t)}\right) \omega_{i}\right] \\
& C=\frac{1}{\Delta t} \phi_{o h} \frac{1}{16 \pi K}\left|\begin{array}{ccc}
x_{1 h} & y_{1 h} & 1 \\
x_{3 h} & y_{3 h} & 1 \\
x_{4 h}-x_{2 h} & y_{4 h}-y_{2 h} & 0
\end{array}\right| \\
& {\left[\sum_{i=1}^{j} K_{0}\left(\frac{r_{i}}{\sqrt{ }(K \Delta t)}\right) \omega_{i}\right] \text {. }}
\end{aligned}
$$

In closed form

$$
\begin{aligned}
B= & \frac{-1_{g}}{2 \pi}\left[\frac{1}{\alpha^{2}}-\frac{1}{\alpha} K_{1}(\alpha)-\frac{\pi}{2}\right. \\
& \left.\times\left[K_{0}(\alpha) L_{-1}(\alpha)-L_{0}(\alpha) K_{-1}(\alpha)\right]\right] \\
B= & \frac{1_{g}}{2 \pi}\left[\frac{1}{\alpha^{2}}-\frac{1}{\alpha} K_{1}(\alpha)\right]
\end{aligned}
$$

where $K_{-1}$ is the modified Bessel function of second Kind and order $-1 ; L_{0}$ is the modified Struve function of zero order; and $L_{-1}$ is the modified Struve function of order -1 .

\section{EXAMPLES}

In order to show some of the properties of the method several examples have been run. The first is (Fig. 1) a square plate with zero initial temperature inside and unity at the boundary for every instant.

The problem has been solved on a quarter of the plate because of the symmetries in which case we had a mixed type problem.
Considering $K=1$, the discretization has 20 elements at the boundary and 25 cells inside the domain.

The results have been compared with the theoretical ones presented for instance by Carslaw and Jaeger [7], and it is important to note the clear influence of the discretization time interval. In order to improve the results we have considered three zones; the first from $t=0.0$ to $t=0.1$ includes the initial rising of the temperature while the second reaches $t=0.75$ and the third $t=3.0$; the considered time intervals have been 0.005 , 0.05 and 0.25 respectively. The accuracy has been good except in the first zone where it was finally necessary to use a time interval $\Delta t=0.002$ in order to model the temperature variation.

Another classical example is a disc (Fig. 2) with the same boundary conditions as before. The discretization contains 18 boundary elements and 23 cells. The results shown correspond to $K=1$. and $\Delta t=0.05$.

A more complex domain is shown in Fig. 3 where the data are the boundary temperatures at the beginning of the process. Again the figure has an axis of symmetry which has been used to reduce the area to be discretized and solved, to a mixed type problem. Discretization has 42 boundary elements and 49 cells. $K=1$ and $\Delta t=0.5$.

Finally a turbine-like shape has been analysed (Fig. 4) using 68 boundary elements and 114 cells and with the same step as before.

\section{GENERAL COMMENTS}

As has been seen, the procedure is simple and efficient and there is the possibility of introducing several improvements.

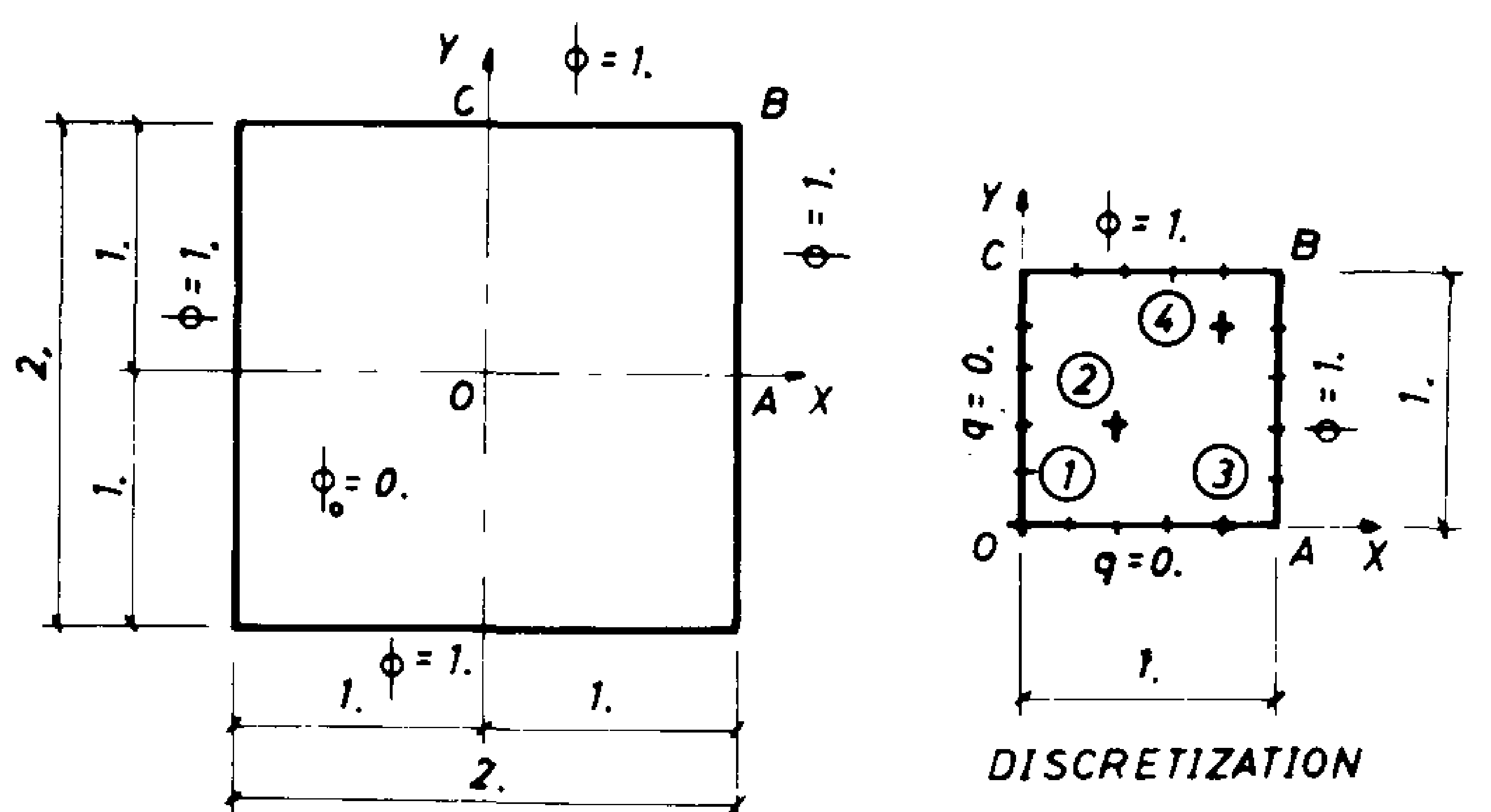

DEFINITION
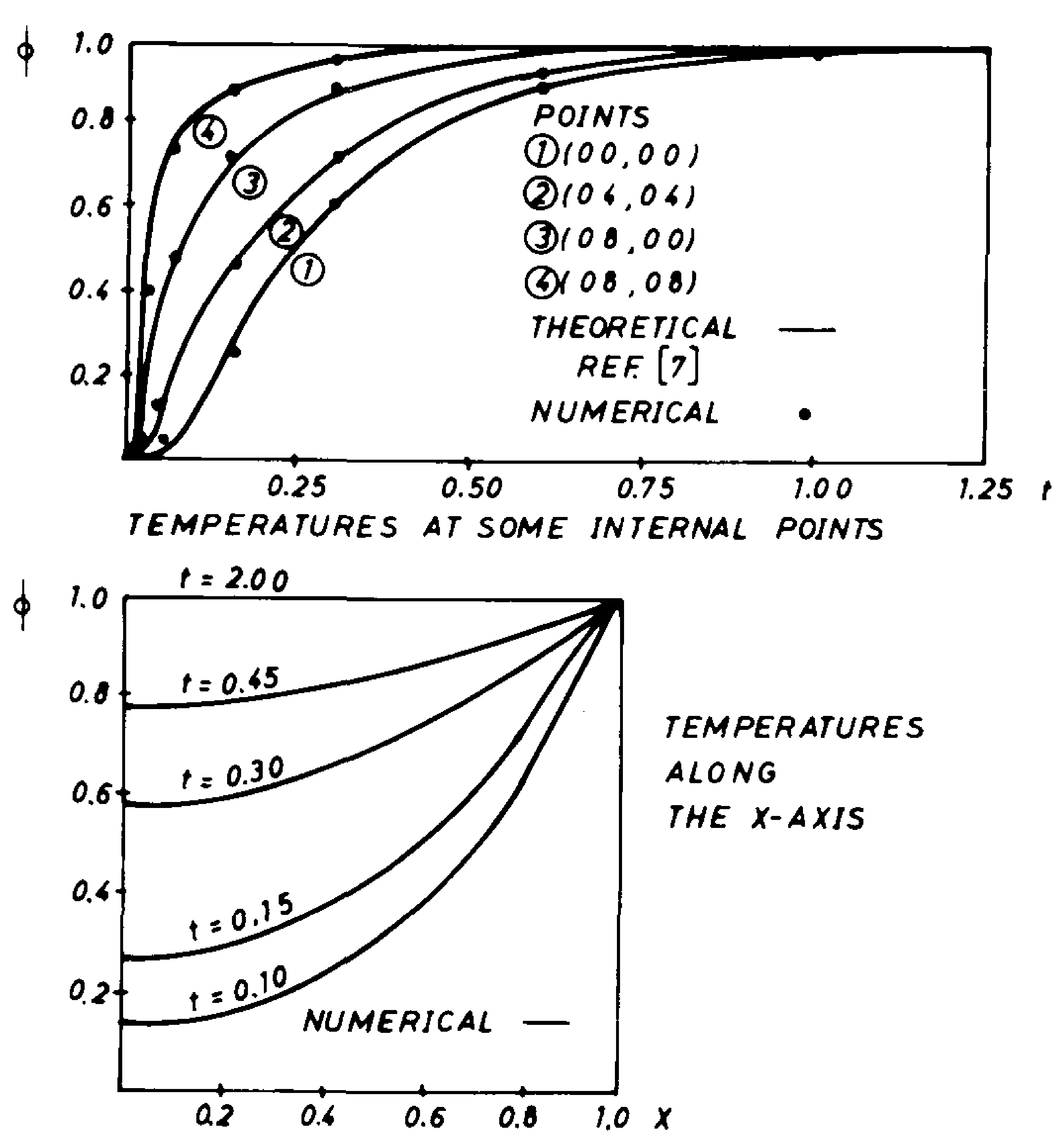

Fig. 1. 
In problems with symmetric geometry subjected to symmetric or antisymmetric actions, it is in general possible to compute and group the corresponding coefficients in an automatic fashion and then elements are not required on the lines of symmetry. Whether or not this technique is advantageous is a matter of the user's taste (see, for instance [10]) although in some cases it produces more accurate results [13].

The most expensive part of the method is the numerical integration. We have not intended to use an adaptive procedure such as explained by Doblare et al.[13] or Lachat et al.[12]. In general the integration in the boundary is made using a standard Gauss rule with 4 points, except in neighbour elements where the results have been found analytically.

The domain integration has always been done numerically using a rule of 36 or 16 points inside each quadrilateral cell, depending on whether or not the cell is in contact with the boundary. The enclosed computer program only uses the first type of integration.

The integration constants have to be computed for each different $\Delta t$. When a unique $\Delta t$ is chosen the integration constants are computed only once during the first iteration, and then stored for subsequent use. The problem then is the election of the interval size in order to maintain an acceptable accuracy without increasing the computation cost by too much.

We have not found any mathematical rule establishing
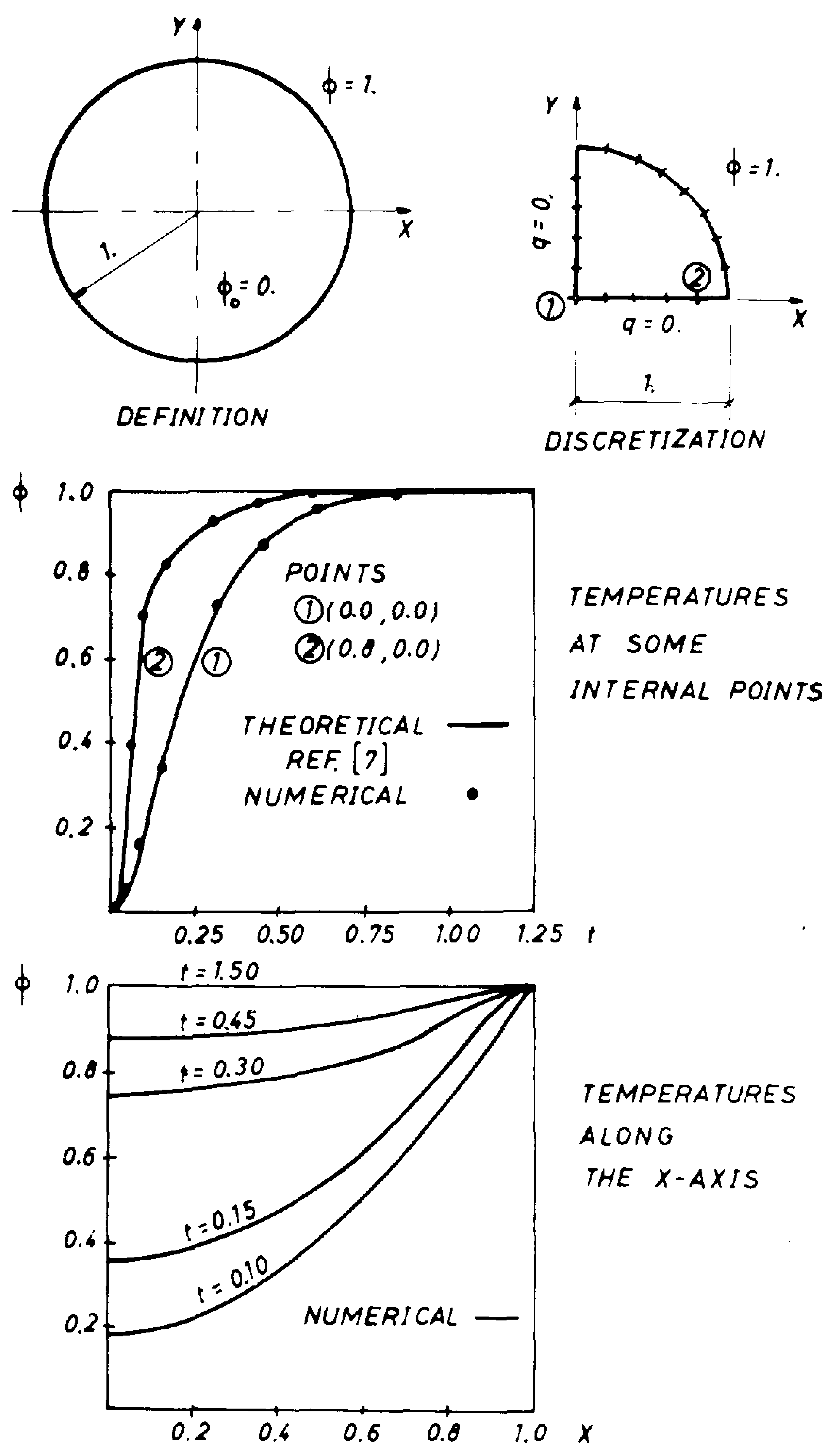

Fig. 2.
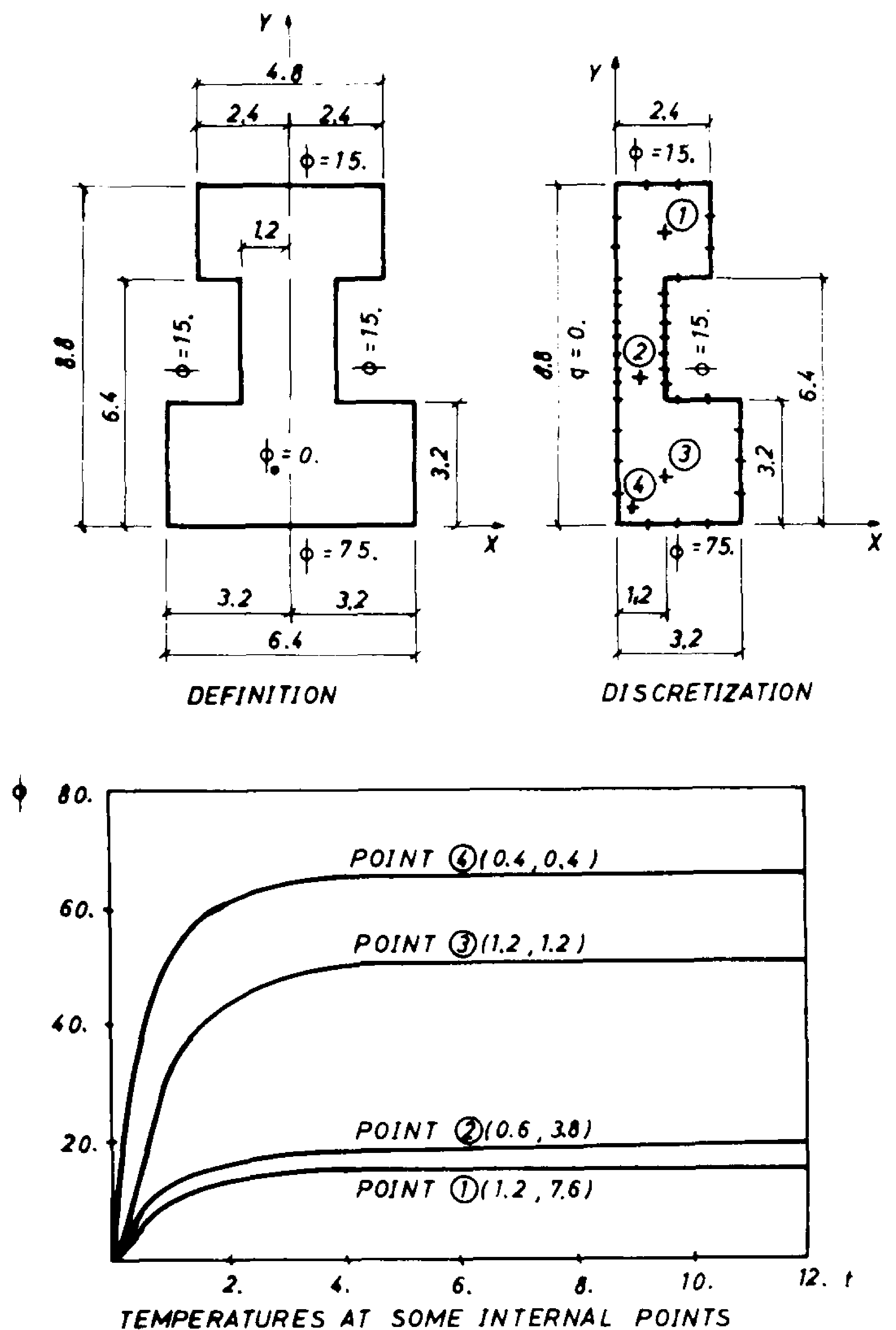

Fig. 3.
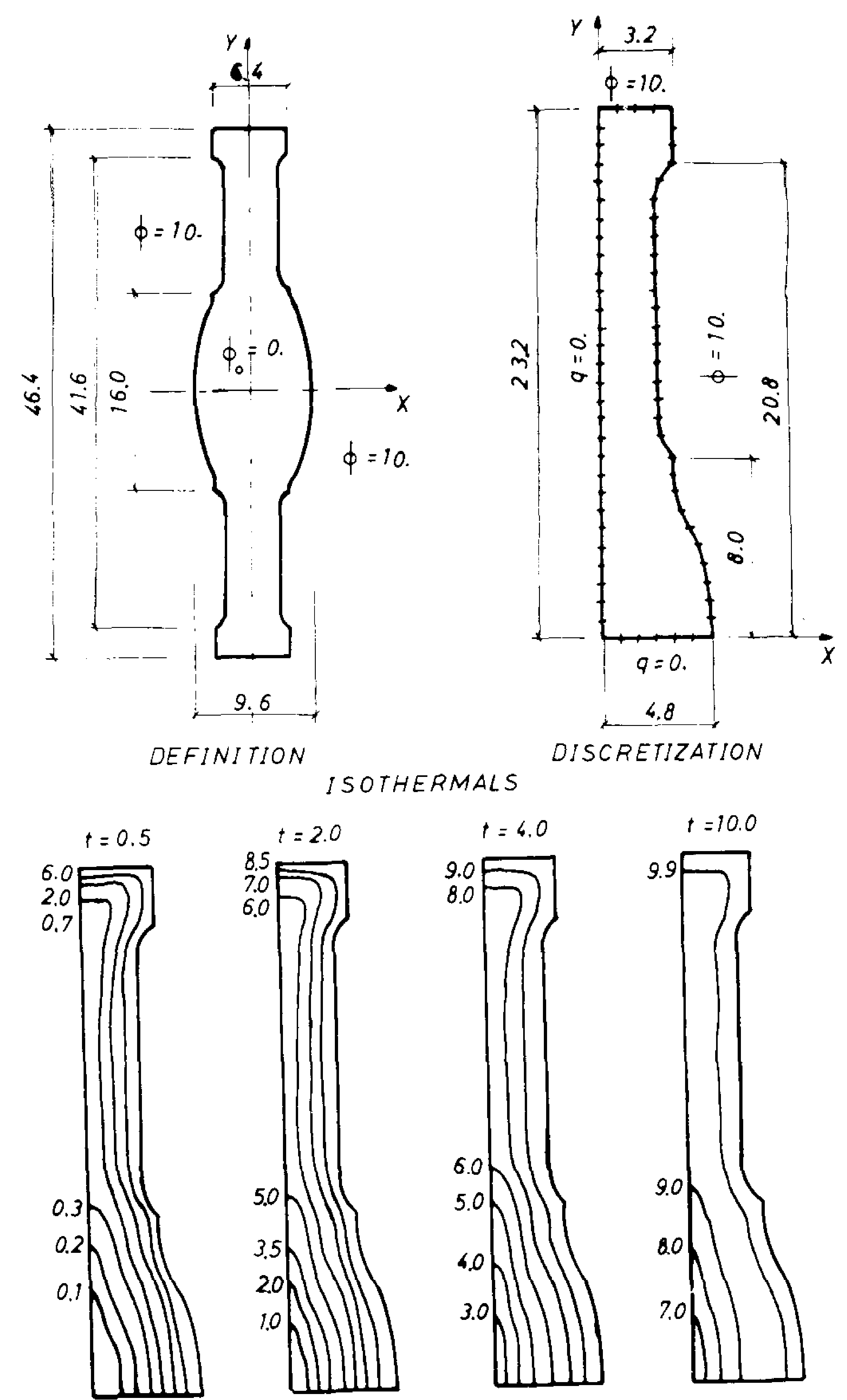

Fig. 4. 
a rigorously founded criterion, but our experience with the method suggests that a good choice is usually

$$
\Delta t=0.0125 \frac{A}{K}
$$

where $A$ is the area enclosed by the domain; $K=k / p c$. With this rule the initial results are a bit polluted but they stabilize after a time of about

$$
t \approx 0.028 \frac{A}{K}
$$

If more precision is needed it is possible to define three ranges of integration as in example 1 . The examples we have run seem to agree well with the following rules:

\section{If}

$$
0 \leqslant t \leqslant 0.025 \frac{A}{K}
$$

take

$$
\Delta t=0.0050 \frac{A}{K}
$$

If

$$
0.025 \frac{A}{K} \leq t \leqslant 0.20 \frac{A}{K}
$$

take

$$
\Delta t=0.0125 \frac{A}{K}
$$

If

$$
t \geqslant 0.20 \frac{A}{K}
$$

take

$$
\Delta t=0.0600 \frac{A}{K}
$$

The first two rules imply 19 intervals. We have found that one more, of the (c) type, is usually enough to reach $95 \%$ of the stationary conditions. Then a good rule with which to start the study is to fix the step number in, say, 21 and to compare the values of the last two steps. These rules are, of course, intended for the transient situation after a sudden application of thermal loads. If the temperature varies it should be necessary to study the problem under consideration. A possible way of attack could be the Fourier analysis of the load and the deter- mination of the step through the velocity of the temperature wave

$$
\nu=\sqrt{ }(2 k w)
$$

where $w$ is the characteristic frequency. The comparison of the wave lengths with the size of the domain will give us an idea of the necessary time step.

\section{CONCLUSIONS}

The examples show the capability of the B.I.E.M. to treat transient potential problems with a discretization of the boundary and the use of integration cells inside the domain.

The time step to be used is problem dependent and a judicious choice has to be made in order to get sound results.

Although the problems analysed present steady-state boundary temperatures, the computer program prepared has the possibility of treating time dependent boundaryconditions with a very simple instruction.

\section{REFERENCES}

1. F. J. Rizzo and D. J. Shippy, A method of solution of certain problems of transient heat conduction. AIAA J. 11, 2004 2009 (1970).

2. R. P. Shaw, An integral equation approach to diffusion. Int. J. Heat Mass Transfer 17, 693-699 (1974).

3. Y. P. Chang, C. S. Kang and D. J. Chen, The use of fundamental Green's functions for the solution of problems of heat conduction in anisotropic media. Int. J. Heat Mass Transfer 16, 1905-1918 (1973).

4. J. C. Lachat and A. Combescure, Laplace transform and boundary integral equations: application to transient heat conduction problems. 1 st Int. Conf. on Innovative Numerical Analysis in Appl. Engng. Versailles (1977).

5. L. C. Wrobel and C. A. Brebbia, The boundary element method for steady-state and transient heat conduction. 1st Int. Conf. on Num. Meth. in Thermal Problems, Swansea (1979).

6. E. Alarcon, A. Martin and F. Paris, Boundary elements in potential and elasticity theory. Comput. Structures 10, 351362 (1979).

7. H. S. Carslaw and J. C. Jaeger, Conduction of Heat in Solids, 2nd Edn. Clarendon Press, Oxford (1969).

8. C. A. Brebbia and S. Walker, Boundary Element Techniques in Engineering. Newnes-Butterworths (1980).

9. L. Wrobel and C. Brebbia, A boundary element solution for time-dependent problems. 2nd Int. Cong. on Numerical Meth. Engng, Dunod. (1980).

10. J. O. Watson, Advanced implementation of the boundary element for two and three-dimensional elastostatics. Developments in Boundary Element Methods, Vol. 1, Chap. 3. Banerjee \& Butterfield. Applied Science Publishers. (1979).

11. M. Boblaré and E. Alarcón, A three-dimensional BEM system. Int. Seminar on Finite Element Systems. Computational Mechanics Center. (1981).

12. J. C. Lachat and J. O. Watson, Effective numerical treatment of boundary integral equations. Int. J. Num. Meth. Engng 10, 991-1105.

13. J. J. Anza and E. Alarcón, The effect of boundary conditions in the solution with B.I.E.M. of 3-D thermoelastic problems. To be published in Software Engineering. 


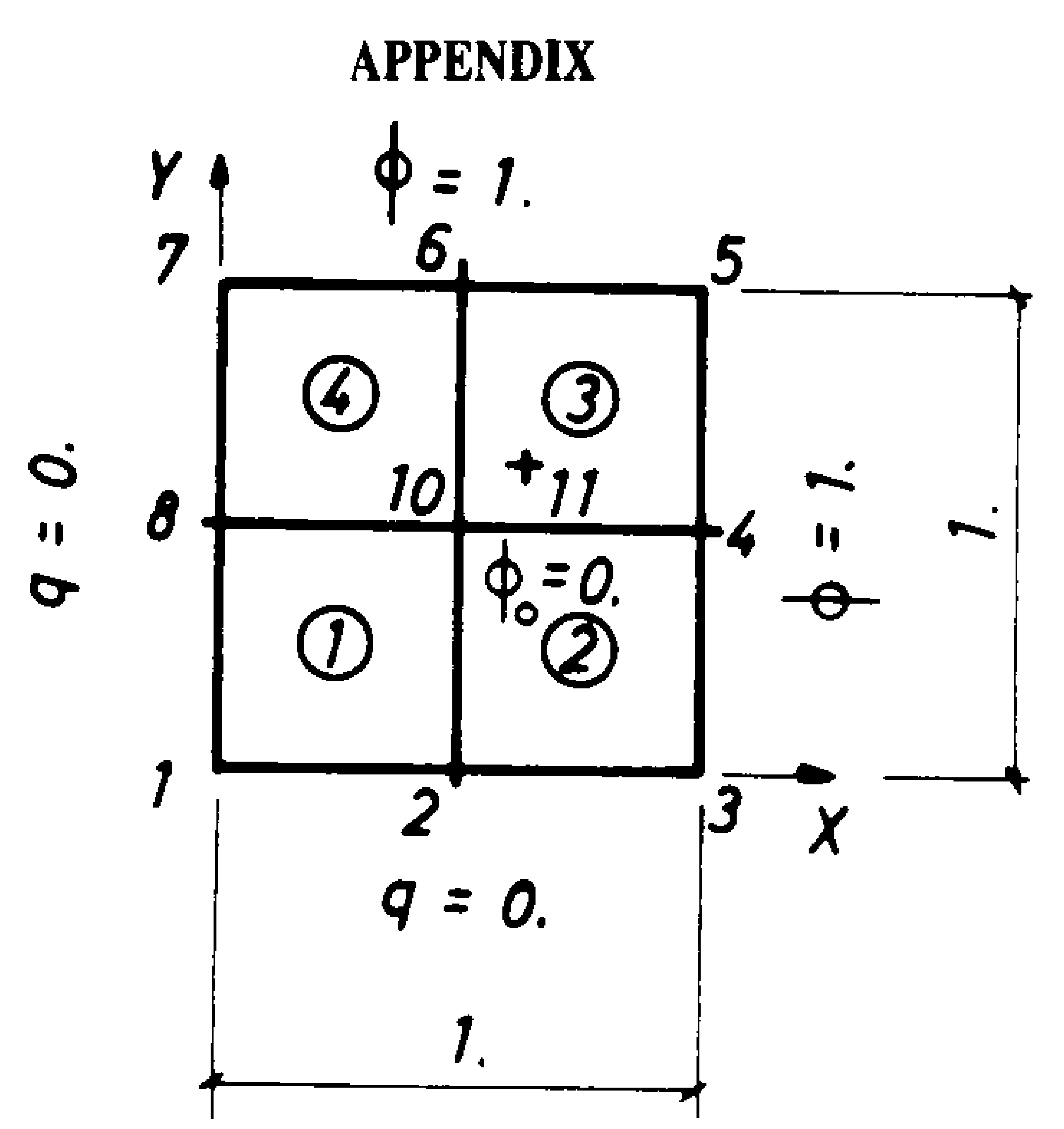

\begin{tabular}{|c|c|c|c|c|c|c|c|c|}
\hline 1: & \multicolumn{3}{|c|}{ SQUARE PLATE } & & & & & \\
\hline 2: & 8 & 10 & 11 & 4 & 0 & 1.0 & 0.05 & 0.1 \\
\hline 3: & 1 & & & 0 & & & & \\
\hline 4: & 3 & & & 0 & & & & \\
\hline 5: & 5 & & & 1 & & & & \\
\hline 6: & 7 & & & 1 & & & & \\
\hline 7: & 9 & & & 0 & & & & \\
\hline 8: & 1 & 1 & & 0 & & 0. & & \\
\hline 9: & 3 & & & 0 & & & & \\
\hline 10: & 5 & 4 & & & & & & \\
\hline 11: & 7 & & & & & 0. & & \\
\hline 12: & 9 & 1 & & 0 & & 0. & & \\
\hline 13: & 10 & & & & & & & \\
\hline 14: & 11 & & & & & & & \\
\hline 15: & 1 & 1 & 2 & 10 & 8 & 0. & & \\
\hline 16: & 2 & 2 & 3 & 4 & 10 & 0. & & \\
\hline 17: & 3 & 10 & 4 & 5 & 6 & 0. & & \\
\hline 18: & 4 & 8 & 10 & 6 & 7 & 0. & & \\
\hline 19: & 0 & 0 & 0 & & & & & \\
\hline
\end{tabular}

Fig. A1.

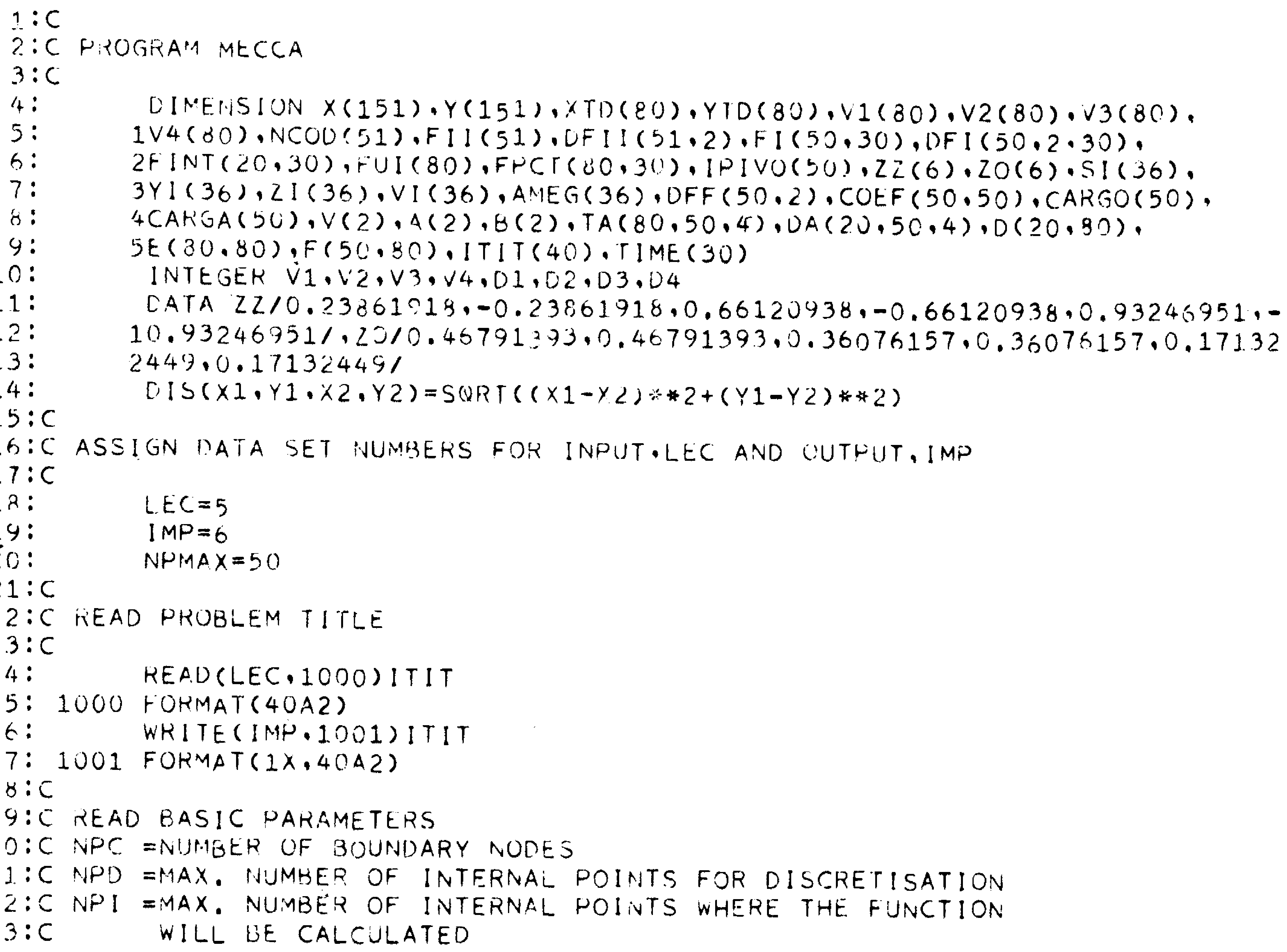


$34: C$ NTD $=$ NUMBER OF INTERNAL CELLS

35:C NCOA=SUPPORT CONDITION FOR NEUHANN PRORLEM

$36: C$ CTER=TERMOMETRIC CONDUCTIVITY

37:C TINC=TIME INTERVAL

$38: C$ TFIN=FINAL TIME

$39: C$

40: READ(LEC.1005)NPC,NPD,NDI,NTU,NCOA.CTER,TINC,TFIN

41: 1005 FORMAT(SI5.5X,3F10.0)

42: WRITE(IMP, 1006)NPC,NPD,NPI,NTS,NCOA,CTER,TINC,TFIN

4.3: 1006 FUKMAT $(2 \wedge, 515.3 F 10.5)$

44: $\quad$ DO $10 \mathrm{I}=1$. NPC

45: $\quad$ FII $(I)=0$.

46: $\quad$ DF $I 1(1,1)=0$.

47: 10 DFII $(1,2)=0$

43: $\quad L=C$

$49: C$

SO:C READ BOUNDARY IODES COORDINATES

b1:C

32: 15 READ(LEC,1010)I,X(I),Y(I)

53: 101U FOKIVAT $(15,5 \times, 2 F 10.0)$

54: IF(L) 20.25 .20

55: 20 NINT $=1-L$

56: $\quad A X=(X(I)-X(L)) / N I N T$

$57:$

$58:$

59:

60:

61:

62:

63:

65:

cio:

$67: \mathrm{C}$

68:C READ BOUNDARY CONDITIONS

69:C NCOD(I)=CODE OF THE NODE I ACCOROING TO THE NEIGHBOURG CONDITIONS

70:C CODE 1 = THE VALUES OF THE FUNETION DERIVATIVE SEFORE AND AFTER OF

$71: C$

$73: C$

HE VAL.JUES OF THE FUNCTION AND

74:C CUDE 3 = THE VALUES OF THE FUNCTION DERIVATIVE BEFORE AND

75:C THE FUNCTION, AKE KNOWN

76:C COUE 4 =THE VALUES OF THE FUNCTION IN

77:C A SHAKP COKNER ARE KNOWN

7\&:C COUE 5 =US 5 BUT IN CONTINUOUS BCIUNDARY

79:C FII I) =THE VALUE OF THE FUNCTION IN THE NODE I IF IT IS KNOWN

$90:($ UFI $1(1,1), 1) F I I(1,2)=$ THE VALUES OF THE FUNCTION DERIVATIVES

$81: C$

BEFOKE AND AFTER IF THEY ARE KNOWN

$8 ?: C$

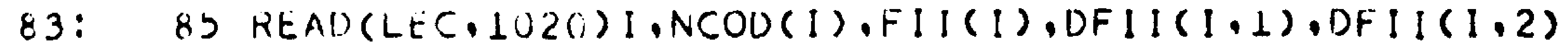

84: 1020 HOHMAT $(215.3 F 10.0)$

35: IF $(I-L-1) 525.55 .50$

86: $\quad 50$ NINT $=1-L$

87: $\quad A X=(F I I(I)-F \| I(L)) / N I N T$

$88:$

$37:$

90:

91:

92:

93:

$44:$

$95:$

$96:$

$97:$

98:

99:

$100:$

$101:$

$102:$

103:

104:

105:

$\therefore 06:$

$107:$

1.0.:

$109:$

$110: 20$

111:

$A Y=(D F|1(1,1)-D F| \mid(L, 2)) / N \mid N T$

5) $L=L+1$

IF $(I-L) 525,70,60$

60 Ir (NCOI)(I).LF.3.AND.NCODD(1).NE.2) GO TO 65

$N C(J)(L)=5$

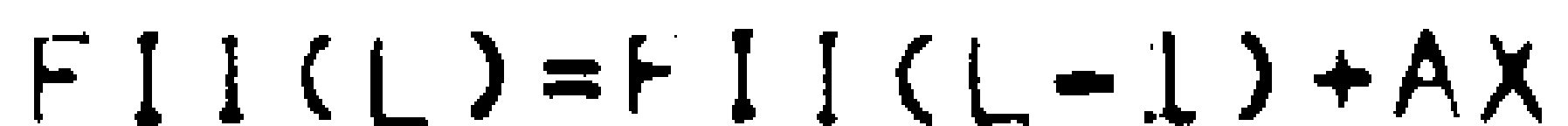

GO 1055

of $N C(B)(L)=1$

$D F I !(L, 1)=D F ! \mid(L-1,2)+A Y$

UF! $1(L, 2)=D F ! I(L, 1)$

GO TC 55

70 I $F($ iNP $(-1) 80,75,85$

$75 F ! I(N P C+1)=F ! I(1)$

LF $11(N P C+1,1)=$ UF $\|(1,1)$

$D F \| !\left(N H^{\prime} C+1,2\right)=D F \perp !(1,2)$

$\left.N C O_{i}\right)(N P C+1)=14 C O D(1)$

OU NKITE $(1 M P \cdot 1025)$

1025 FORMAT (IH3.5X.'RO!JNOARY NODES-BOUNDARY CONDITIONS

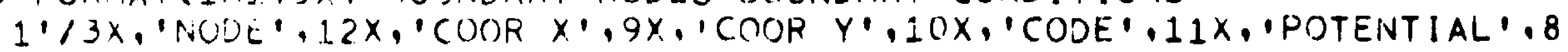
$2 \times$.'FLUX BEFOIE', 9X, 'FLUX AFTFR')

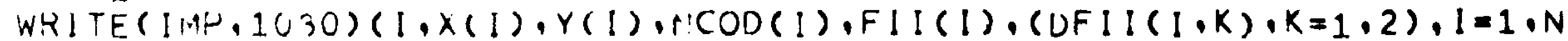
IP()

2030 FORIMAT $(2 x, 15,3 x, 2 F 15.4,8 x, 13,1 \times, 3 F 20.5)$

CONTINUE

$52 b$ CONTINUt 
114:C REAO INTEKNAL POINTS(EISCRESITATION)COORDINATES

$115: C$

116: $\quad \operatorname{READ}(L E C, 1026)(X(I P D), Y(I P D), I P D=N P C+2, N P D)$

117: 1026 FOKMAT (1OX,2F10,0)

118: WRITE(IMP,1011)

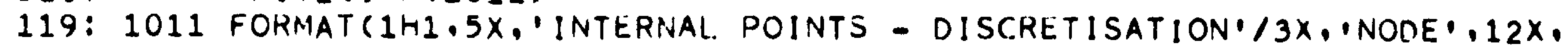

120: $\quad$ I'COOR $X^{\prime}, 9 X^{\prime} \cdot$ COOR $\left.Y^{\prime}\right)$

121: WRITE(IMP,1012)(IPD,X(IPD),Y(IPD), IPD=PPC+2,NPD)

1)2: 1012 FORMAT $(2 X, 15,3 X, 2 F 15,4)$

123: IF (NPI,EQ.NPD)GO TO 1032

$124: C$

$125: C$ READ INTEKNAL POINTS(WHERE THE FUNCTION WILL BE CALCULATEDICOORDINATES $126: C$

127: $\quad \operatorname{READ}(L E C, 1026)(X(|P|), Y(I P I), I P I=N P D+1, N P \mid)$

128: WRITE(IMP,1031)

129: 1031 FORMAT(1H1,5X,'INTERNAL POINTS - POTENTIAL CALCULATION'/3X,'NODE',

130: $\quad 112 X_{1} \cdot$ COOR $X^{\prime}, 9 X_{1} \cdot$ COOR $\left.Y^{\prime}\right)$

131: $\quad W R I T E(I M P, 1012)(I P I, X(I P I), Y(I P I), I P I=N P D+1, N P I)$

$132: \mathrm{C}$

133:C READ INTEKNAL CELLS INCIDENCES AIND INITIAL POTENTIAL

$134: C$

135: 1032 READ(LEC,1040)(V1 (ITD), V2(ITO),V3(ITD),V4(ITO),FUI(ITD), ITD=1 NTD)

136: 1040 FORMAT $(5 X, 4 ! 5,5 X, 1 F 10.0)$

137: WRITE(IMP,1050)

138: 1050 FORMAT (1H1,5X,'CELLS-INCIDENCES $/ 7 X_{1}$, CELL',16X, 'VER 1 '

139: 1.9X,'VEK 2',9X,'VEK 3',9X,'VEK 4',9X,'INITIAL POTENTIAL')

140: WRITE(IMF,1060)(ITI),VI(ITD),V2(ITD),V3(ITD),V4 (ITD),FUI (ITD), ITD =1

141: $1, N T D)$

142: 1060 FOKMAT $(6 x, 15,14 x, 15,9 x, 15,9 x, 15,9 x, 15,13 x, 1 F 10,5)$

143: DO 90 ITO=1.NTD

144: $\quad$ DI $=11($ ITU $)$

1.45: $\quad 02=V 2(I T())$

146: $\quad 03=V 3(I T D)$

147: $\quad 04=V 4(I T D)$

148 :

$149:$

$150:$

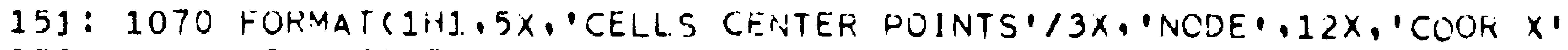

152: $\left.\quad 1.9 \times \cdot \cdot \operatorname{COOR} Y^{\circ}\right)$

153: $\quad$ RITE(IMP,1075)(ITK,XTU(ITK),YTO(ITK),ITR=1,NTD)

154: 1075 FORMAT $(2 x, 15,3 x, 2+15.4)$

$155: C$

$156: C$ RE.AD COUES

$157: C$

158: REAL(LEC.1030) NCODT,NCCDD.NCOTT.CC

159: 1090 FOKMAT $(315.175 .0)$

160: IF(NCUDT)92,92.91

16.1: 91 WRITE (I'PP,1091)

162: $10 Y 1$ FORMATCSX, 'NOF IMPRESION HOTENTIAL OF CENTER HOINTS OF CELLS'

163: 1)

J.́ं: $\quad$ GO rO 93

265: 92 WRITE(IHP,1092)

166: 1092 FORMAT(5X, IMPHESION POTENTIAL. OF (ENTER POINTS OF CELLS')

167: 93 IF(NCUDU) 94.34 .95

168: 94 WRITE (IIAN,1093)

169: 1093 FOR'NAT(5X.'NOT CALCIILATIGN CELLS VERTEX FOTENTIAL')

170: $\quad$ GO TÓ 9y

171: 95 NRITE(I!1P.1094)

172: 1094 FURIATT(5X, 'CALCULATION CELLS VERTEA RCTENTIAL')

173: 99 IF (NCOTT) 101.101.10?

174: 101 WRITE (IMP.1095)

175: 1095 FORMAT(5X, 'DOMAIN INITIAL POTENTIAL EQUAL LERO')

176: GO TO 103

177: 102 WRITE(1.1H,1096)

178: 1096 FOKMAT(5X.'DOMAIN INITIAL POTENTIAL NOF EQUAL ZERO')

$179: C$

180:C LOAD FACTUR. FOK UNIFOKM VAFIABLE BOUNOARY CONOITIONS

$181: C$

182: 103 WRITE(IMP,1097)CC.

183: 1097 FOKMAT $\left(3 X_{1}\right.$ 'LOAD FACTOH=1.1F 5.2$)$

184: WIRITE(IMP,1?00)ITIT

185: 1200 FORIAAT $\left(1 H 1.10 \times .40 A 2 / 10 \times .80\left(.^{\prime} * 1\right)\right)$

186: $\quad$ NTIT $=1+T F I N / T I N C$

187: $\quad I I=1$

$188: C$

189:C CALCLLATIUN INTEKPOLATIOIN FIINCTIONS

190:C

191:

$00900 \mathrm{~J}=1.0$ 
192:

$193:$

194:

$1.75:$

196:

197:

133:

199:

200:

201:

$202: c$

203:C INITIALISATIUR: TIME INTEGIRATION

¿04:C

$205:$

206:

207:

208:

2C9:

$21 \cup: C$

211:C

21: :C

2].3:

214:

23.5:

2. 6:

ข1.7:

218:

215:

2\%0:

2.2.1:

<? 2:C

2?3:C

2) 5 :

2. $26:$

227:

220:

22.9:

230:

231:

232:

$233:$

234:C

2.35:C

236:C

237:

238:

$239:$

240:

241:

242:

243:

244:

245:

246:

247 :

248:

249:

250:

251:

$252:$

253:

254:

255:

256:C

257:C THE INTEGKATION PESULTS AKE PLACEL IN THE COEFFICIENTS MATRIX

258:C OR IIN THE LJAD VECTOR ACCORDING TO THE CODE OF THE NODES

$259: \mathrm{C}$

260:

261:

262:

$263:$

264:

265:

265:

267:

268:

269:

$270:$

U) $905 k=1,0$

$S !(11)=0.25 *(1-Z Z(J)) *(1-2 L(k))$

$Y I(I I)=0.25 *(1+Z Z(J)) *(1-Z Z(K))$

$Z !(I I)=0.25 *(1+? L(J)) *(1+Z L(K))$

$V I(I !)=0.65 *(1-22(J)) *(1+2 . L(K))$

$\operatorname{AME}(j(11)=2 O(J) * Z \mathcal{L}(K)$

$I I=I I+1$

OOS CONTINUE

00 CONTINUF.

$F C=1$.

DU $333 \quad I T=1 \leftrightarrow \mu T T T$

00 ( $9, J=1 . N 0 \mathrm{C}$

$F I(J \cdot \mid T)=F \perp I(J) * F C$

DFI $(J, 1,1 T)=U F \perp \perp(J, 1) * F C$

$96 \operatorname{DF} I(J \cdot 2 \cdot 1 T)=L F I 1(J, 2) * F C$

NTEGKATILIN ON IHE BOUNDATY

DO $200 \mathrm{NON}(\mathrm{NO}=1, \mathrm{NH} \mathrm{C}$

IF $(1 T-1) 001 \cdot 601,502$

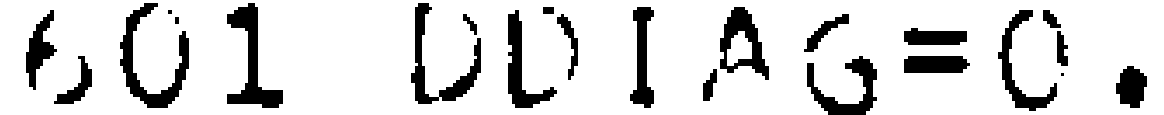

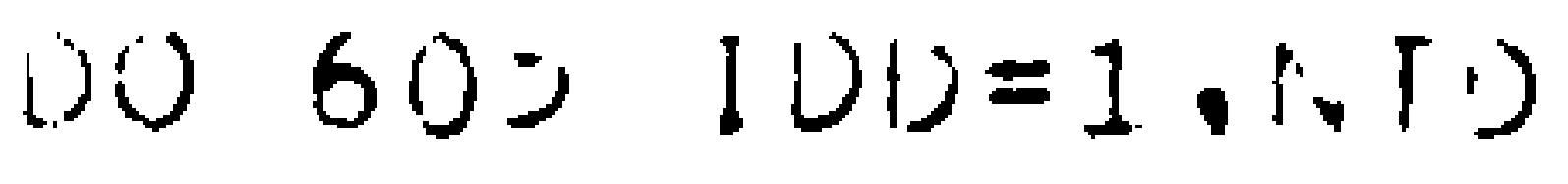

$1=\vee 1(100)$

$02=\vee 2(11) \cup)$

$03=\vee 3(1, j i)$

$04=V+(1 ;)(1)$

$P P R T=1$.

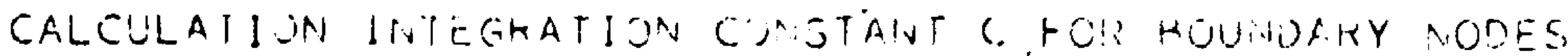

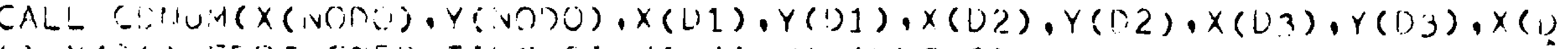
$14), Y(U A), F D C T,(T E R, T I N C, S I, Y I, / 1, V 1, A, \cdot i t, G, G)$

$F(P j)(D, D U U)=C_{3}$

rub OUIAG=DidaG+o

DO $100 \quad 1=1, \operatorname{lin} P$

100) $\operatorname{COt} F(\mathrm{NODO}, 1)=0$.

CDI $A G=0$.

$C=0$.

CARGO(NOUO) $=0$.

CALCULATION INTEGRATION CONSTANTS A,B FOR BOUNDARY NOUES

DO 190 IELEM=1,NPC

IF (IELEN.EQ.NODO)GO TO 152

IF ( (ILLEM+1),E(N.NODO)GO TO 151

IF(IELEM,EQ.NPC. ANO, NODO,EQ.1)GO TO 151

CALL ABINUM(X(NODO),Y(NODO),X(IELEM),Y(IELEM),X(IELEM+1),

$1 Y(I E L E M+1), C T E R, T I N C, A(1), A(2), B(1), E(2))$

GO TO 153

152 CALL. ABANA (X(NODO), Y (NODO),X(IELEM+1), Y (IELEM+1),CTER,TINC,A(1),AC

$12) \cdot B(1) \cdot B(2))$

GO TO 153

151 CALL ABANA $(X(I E L E M), Y(I E L E M), X(N O U O), Y(N O D O), C T E R, T I N C, A(1), A(2), B$

$1(1), B(2))$

$A X=B(1)$

$B(1)=B(2)$

$B(2)=A x$

$153 C D \backslash A G=C D I A G+A(1)+A(2)$

DO $179 \quad K=1,2$

$K N=1 E L E M+K-1$

$I F(K N \cdot F Q \cdot N P C+1) K i N=1$

GO TO $(1,2 \cdot 3 \cdot 4 \cdot 6), N C O O(K N)$

$1 C A R G O(N O U O)=C A R G O(N O C O)+B(K) * D F I(K N \cdot j-K, I T)$

$\operatorname{COEF}(N O D O, K N)=\operatorname{COEF}(N O D O, K N)+A(K)$

GO TO 179

2 IF (K.EQ.2)GO TO 160

$165 \mathrm{CARGO}(N O D O)=C A R G O(N O D O)+B(K) * D F I(K N \cdot 3-K, I T)-A(K) * F I(K N, I T)$ GO TO 179

3 IF (K,EQ,2)GO TO 165

160 CARGO $(N O L C)=C A R G O(N O D O)-A(K) * F I(K N, I T)$

COEF $($ INODO, KN $)=\operatorname{COEF}(N O D O, K N)-B(K)$

GO TO 179 


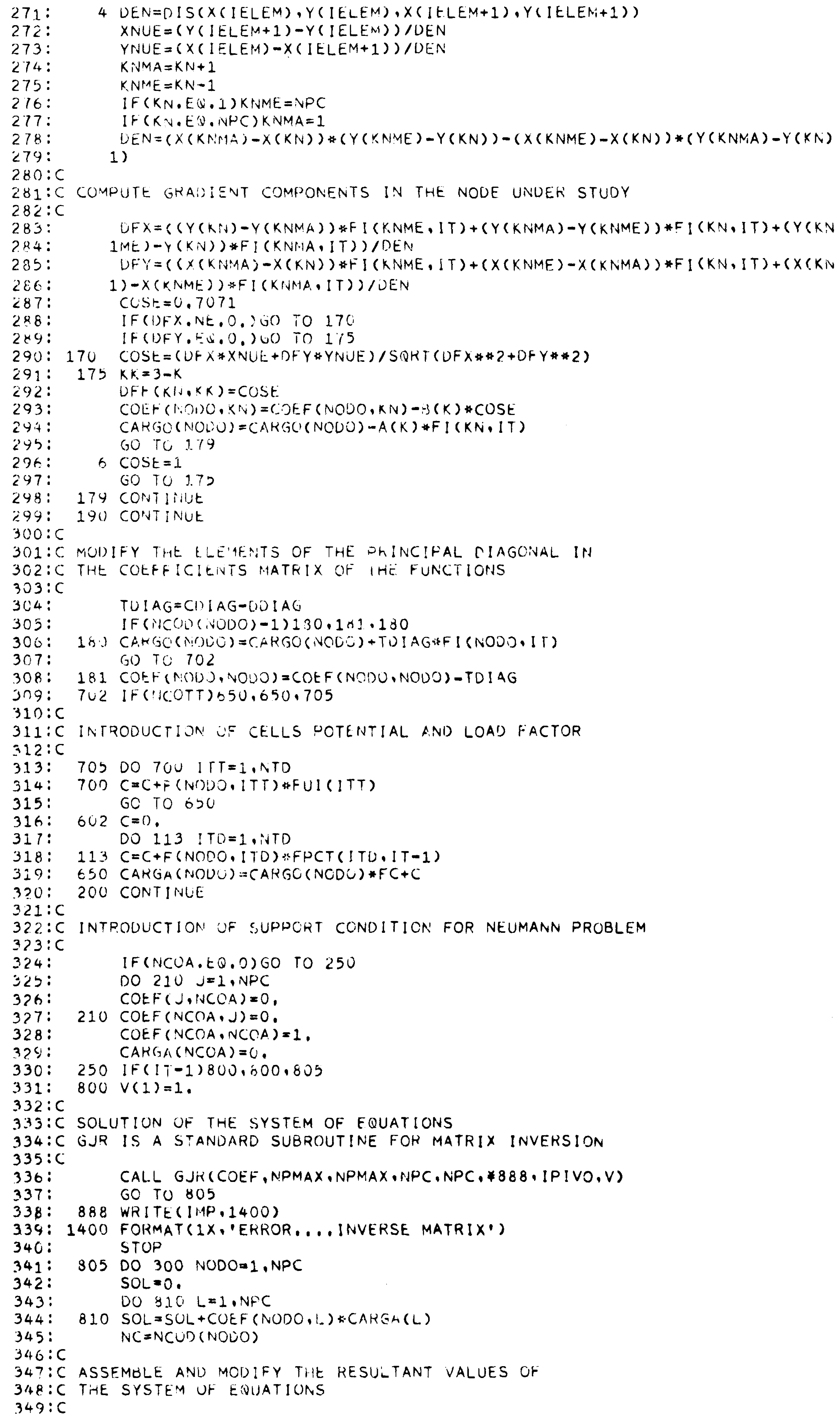


350:

351:

352:

353 :

354

355:

$356:$

$357:$

$358:$

359:

360:

361:

$362:$

363:

364:

365:

366

367:

368:

369

370:

371:

$372: C$

373:C

374:C

375:

376:

377:

$378: \mathrm{C}$

379:C EALCULATION INTEGRATION CONSTANTS A.B

$380: C$

$38.1:$

382:

$383:$

$384:$

$395:$

$386:$

$337:$

$388: C$

$389: C$

$330: C$

391:

$392:$

393:

394:

395

396:

397 :

398:

$399:$

400

401:

$402:$

403:

404:

405:

$406:$

407:

408:

409:

410

411:

412:

$413:$

414:

415:C

416:C COMPUTE FUNCTION VALUE IN CENTER NODES OF. CELLS

$417: C$

418: 399 DO 400 ITD $=1$,NTD

419:

420:

$421: C$

422:C CALCULATION INTEGRATION CONSTANTS A,B

$423: C$

$424:$

$425:$

426:

427:

428:

DO $610 \quad J=1, A . P C$ 12),B(1),B(2))

$D A(M M-M, J, 1)=A(1)$

$D A(M ! M M, J, 2)=A(2)$

UA $(M M M \cdot J, 3)=B(1)$

$610 D A(M M M, J, 4)=B(2)$

CALCULATION INTEgRATION CONSTANT C

DO $710 \quad J J O=1 . N T D$

$D 1=V 1(J J D)$

$D 2=\sqrt{ } 2(J J O)$

$D 3=V 3(J J 0)$

$04=V 4(J J U)$

I,Y $(04), F P P T, C T E R, T I N C, S I, Y I, Z 1, V I, A M E G, G)$

$710 D(M M P, J J D)=G$

IF (NCOTT $) 424.424 .7 C 6$

706 DO $777 \quad J[J=1, N T D$

$777 C=C+D(M: M i M, J[J) * F \cup I(J D J)$

GO TO $4 ? .4$

$422 C=0$.

DO $423 \quad J T D=1$. NTO

$423 C=C+D(M M M, J T U) * F P C T(J T D, I T-1)$

$424 \mathrm{HPCT}=0$.

DO $430 \quad J=1$. NFC

$J J=J+1$

$I F(J, E Q, I J P C) J J=1$ $1 F I(J, 2, I T)+D A(M M M, J, 4) * D F I(J J, 1, I T)$

FINT (MMM, I T) $=H P C T+C$

$420 \quad 1 N T=I N T+1$

IF $(I T-1) 401,401.402$

$401 C=0$.

DO $615 \mathrm{~J}=1, N P C$

1), $A(2), 8(1), O(2))$

$T A(1 T 0,1,1)=A(1)$

$T A(I T O, J, 2)=A(2)$

CALL ABNUNI(X(INT),Y(INT),X(J),Y(J),X(J+1),Y(J+1),CTER,TINC,A(1),AC

CALL CDNUM(X(INT),Y(INT),X(D1),Y(D1),X(D2),Y(D2),X(D3),Y(D3),X(D4)

$430 H P C T=H P C T-D A(M M M, J, 1) * F I(J, I T)-D A(M M M, J, 2) * F I(J J, I T)+D A(M M M, J, 3) * D$

CALL ASNUM(XTD(ITD),YTD(ITD), X(J),Y(J),X(J+1),Y(J+1),CTER,TINC,A(1 


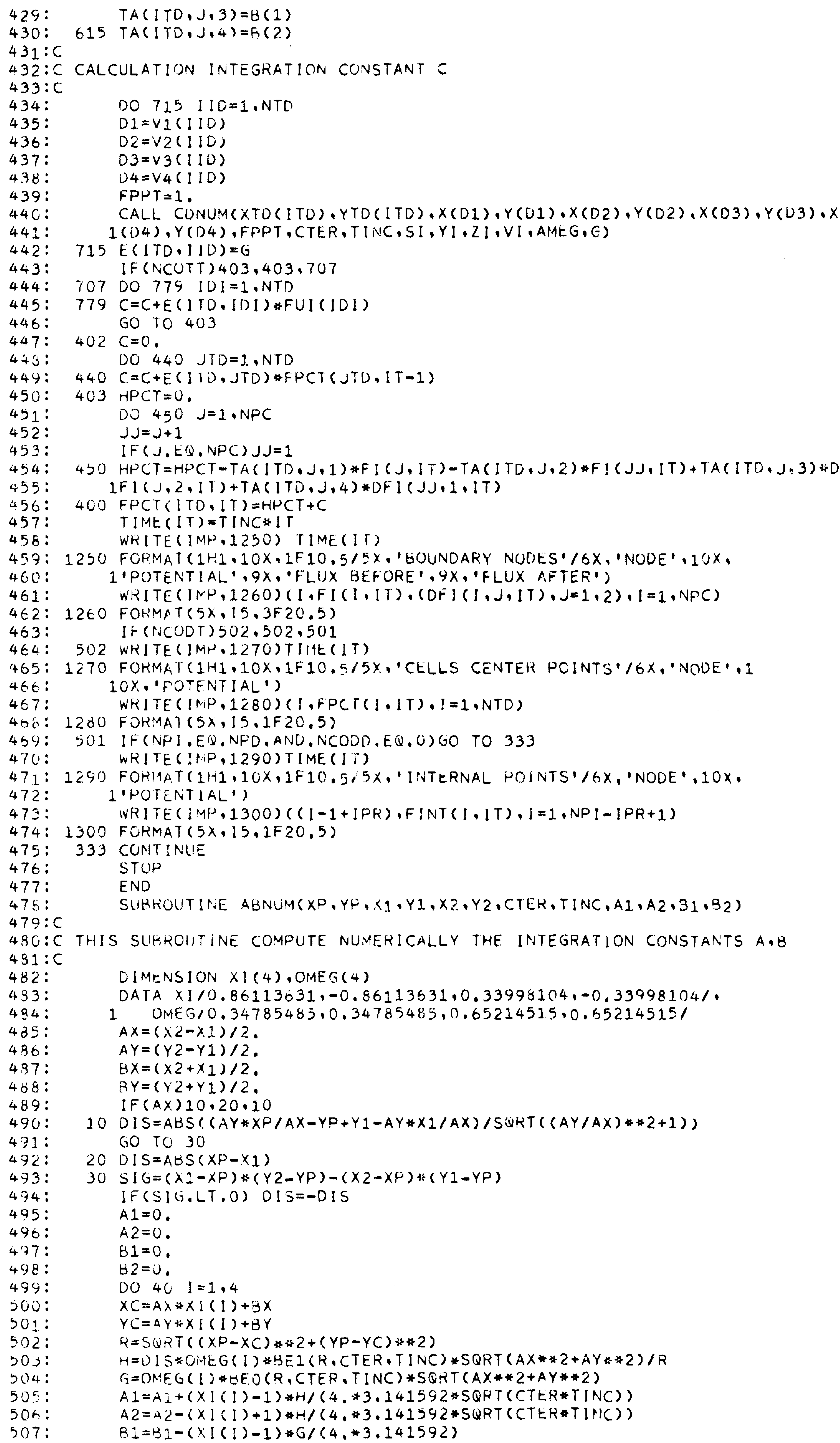


$208:$

509:

510:

51j:

$512: C$

513:C

214:C

215:

b16:

517 :

518:

519:

5\%:

ว2.1:

5?2:

$523:$

$524:$

525:

$526:$

527 :

$528: C$

$225: C$

$530: C$

531 :

532:

$533:$

$534:$

535:

$536:$

537:

$538:$

539 :

540:

541:

$542:$

$243:$

544:

545:

546:

547:

$548: \mathrm{C}$

549:C THIS FUNCTION COMPITE THE VALUL OF

55::C THE MOUIFIEO UESSEL FUNCTION SECOND KIND ORDF.K O

$551: C$

$552:$

$353:$

$554:$

$55 \mathrm{~s}:$

$556:$

$557:$

$558:$

$554:$

$560:$

56.1:

502 :

563:

564:

565:

566:

367:

265:

509:

$270:$

371:

$572:$

ว73:

274:

575:

576:

$577:$

378:

579:C

580:C

HIS FUNCTION COMPUTE THE VALUE OF
THE MODIFIED BESSEL FUNCTION SECOND KIND OKOER 1

580:C THIS FUNCTION COMPUTE THE VALUE OF
$581: C$ THE MODIFIED BESSEL FUNCTION SECOND KIND OKOER 1

582:C

583:

584:

585:

$586:$

$4032=82+(X 1(1)+1) * G /(4 . * 3.141592)$

KETUR'

ENL

SUBROUTINE ABANA (X1,Y1,X2,Y2, CTER,TIINC,A1, A2,B1,B2)

$A 1=0$.

$A 2=0$,

$H=S W R T((X 2-X 1) * 2 * 2+(Y)-Y 1) * 2)$

DEOCIS, (TER, TINC) *STI (UIS, CTER, TINC)

$A L F=0 I S / S Q R T(C T F K * T I I N C)$

$S=(A L F * a t 1(D) 1 S, C T F R, T I N C)-1) / A L F * * 2$

$=(v+S) * 01 S /(2.33,141592)$

$B 2=-S * D I S /(2.3 * 3.1415+2)$

ETURN

$1, \angle I, V I, A M E(j, G)$

OIMENSION SI(36), YI (36), ZI (36), VI (36), AMEG (36)

$H=C$

$A R S(A A C O)$

$X C=X 1$ i*SI $(I)+X 2 * Y I(I)+X 3 * L I(I)+X 4 * V I(1)$

$Y C=Y 1 * S I(1)+Y 2 * Y I(I)+Y 3 * L I(I)+Y 4 * V I(I)$

$R=S Q F T((X P-X C) * 2+(Y P-Y C) * 2)$

$S=1 / 10$; \# $\#$

IF $(P-5) \quad 30 \cdot 30,10$

$100=R E O(R, C T E R, T I N C)$ \& AMES(I)

$H=H+D$

30 CONT I IVlt

$G=(H /(6.283184 *$ CTER $* T I N()) * A A C O$

RETURN

ENC

DOUBLE PRECISION OP, XL,XT,TL, CO,FKO,E

$x=D$ I S/SIRT (CTEK KT INC)

I $F(x-4) ,5 \cdot 3 \cdot 3$

$3 D P=X$

$1732421875 / \mathrm{DP} * 3+0.1121520996 /$ (DP**4)

GO TO 30

$5 \mathrm{OP}=\mathrm{x} / 2$

$F K . O=-10.577216649-0 L O G(O H)$

$E=C$.

$X Z=1$

DO $20 \quad K=1,60$

$E=t+1 \cdot / x$

$X T=E-U .277216649-U L C G(D H)$

$x Z=x Z *(X * 2 / 4,) / K * 2 * 2$

$T Z=X T * X Z$

$C O=F K C / 10, * 10$

IF (OABS (TZ)-DABS $(C O)) 30,10 \cdot 10$

$10+K O=F K O+T Z$

20 CONTINUE

WRITE $(6,100)$

100 FORMAT $1 X$.'ERROR..SERIES BEO IS NOT FINISHED')

STOP

$30 B E O=F K O$

RETURN

END

FUNCTION BEI(DIS.CTER,TINC)

COUBLE PRECISION DP,E, XZ,XT,TL,FKI,CO

$X=0 ! S / S(N K T$ (CTER $\#$ INC)

I $F(X-4) 5,3,$,

$3 \mathrm{DP}=\mathrm{X}$

HIS SUGRUIT INE COMPUTE anAlITICALLy the INTEgRATION CONSTANT B

HIS SURRUIJINE COMPLTE INUNEKICALLY THE INTEGRATION CONSTANT C

. $125 *\left(Y_{1} *(X 4-X 2)+X .3 *\left(Y_{4}-Y_{2}\right)-Y_{3} *(X 4-X 2)-X 1 *\left(Y_{4}-Y_{2}\right)\right)$

$F K O=(1.253314 * D E X P(-D P) / S Q R T(D P)) *(1 .-0.125 / D P+0.0703125 / D P * * 2-0.0$ 


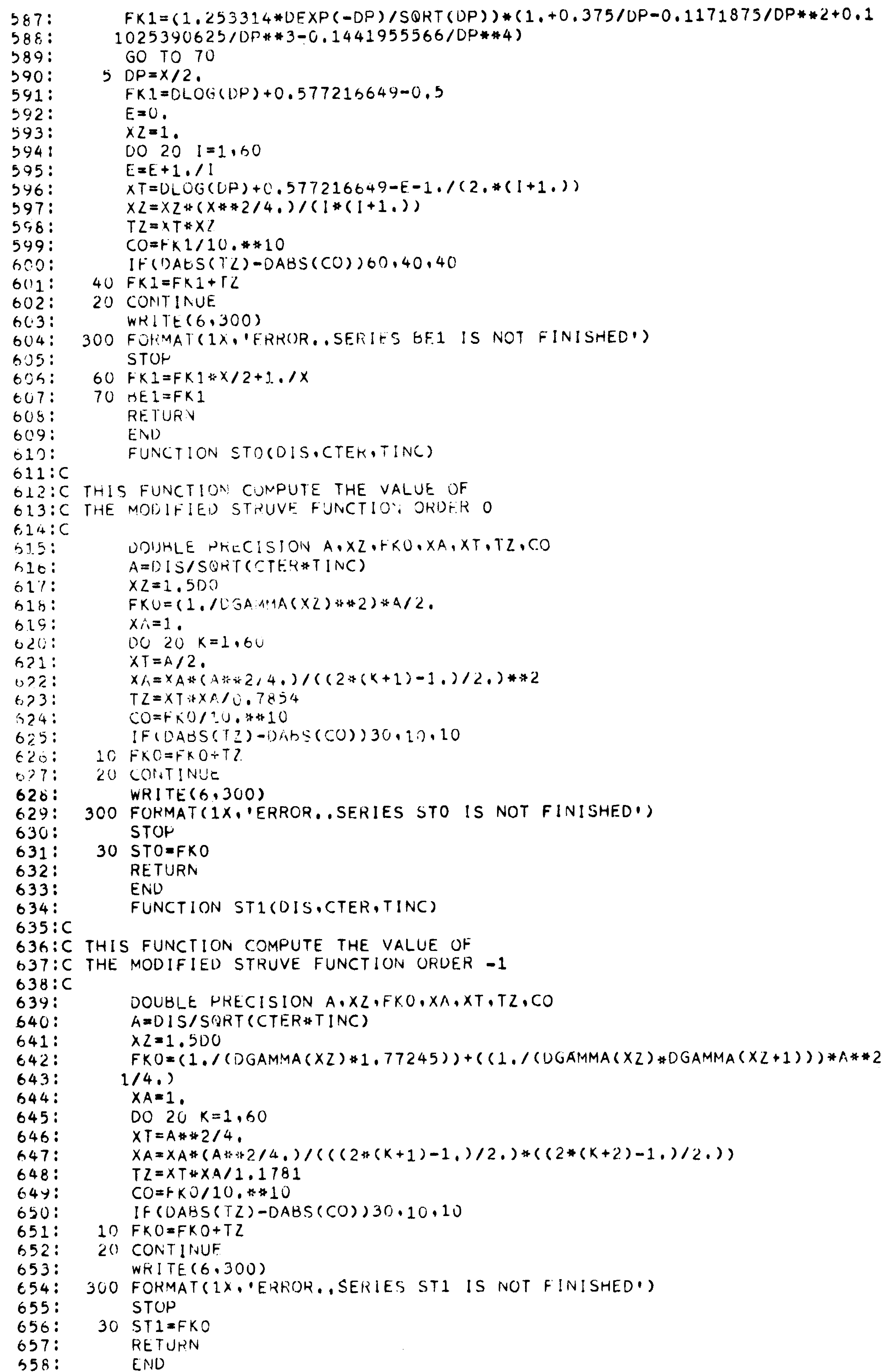

